\title{
Structural reliability as applied to highway bridges
}

Andrzej S Nowak and Maria M Szerszen

University of Michigan, USA

\author{
Summary \\ The paper presents the application of reliability \\ methods in the development of a load and \\ resistance factor design (LRFD) bridge codes. \\ Structural performance is measured in terms of the \\ reliability index. Load and resistance models are \\ summarized. An important step is the selection of
}

Prog. Struct. Engng Mater. 2000; 2:218-224

\section{Introduction}

The structural reliability can be applied in the design of new bridges and evaluation of existing ones. A new generation of design codes is based on probabilistic models of loads and resistance. Examples include:

AASHTO LRFD code[1] OHNDC[2], Eurocode[3] and CHBDC[4]. In general, reliability-based design can be more efficient. It makes it easier to achieve either

- for a given cost, design a more reliable structure, or

- for a given reliability, design a more economical structure.

Reliability can be considered as a rational evaluation criterion. It provides a good basis for the decision about repair, rehabilitation or replacement.

Deterministic approach is based on analysis of individual components. A structure can be

condemned when a nominal value of load exceeds the nominal load-carrying capacity. But, in most cases, a structure is a system of components. Furthermore, when a component reaches its ultimate capacity, it is not necessarily eliminated from the structure. It continues to resist the load but additional loads are distributed to other components. System reliability provides a methodology to establish the relationship between the reliability of an element and reliability of a system. the target reliability index and calculation of load and resistance factors. Load and resistance factors are derived so that the reliability of bridges designed using the proposed provisions is at the predefined target level.

The modern reliability analysis methods have been developed since the late 1960s. They are based on theory of probability and statistics. However, current approach to safety in the design and construction is a result of an evolution which took many centuries. The practical applications of the reliability analysis were not possible until the pioneering work of Cornell, Lind, and Ang in the end of 1960s and early 1970s. Cornell proposed a second-moment reliability index in 1969. Hasofer and Lind formulated a definition of format-invariant reliability index[5]. An efficient numerical procedure was formulated for calculation of the reliability index by Rackwitz \& Fiessler[6]. Other important contributions were made by Veneziano, Rosenblueth, Esteva, Turkstra, Moses, and Ang. Their work was further improved by Der Kiuregian, Frangopol, Fujino, Furuta, Yao, Brown, Aayub, Blockley, Stubbs and Mathieu. The developed theoretical work has been presented in books as for example by Thoft-Christensen \& Baker[7], Augusti, Baratta \& Ciascati[8], Madsen et al[9] Ang \& Tang[10], Melchers [11], and Thoft-Christensen \& Murotsu[12].

By the end of 1970s, the reliability methods reached a degree of maturity and they are now available for applications. In the coming years, one can expect a further acceleration in the development of analytical methods to model the behavior of structural systems. The real change can be expected by focusing on

\section{Abbreviations}

AASHTO $=$ American Association of State Highway and Transportation Officials

$\mathrm{CHBDC}=$ Canadian Highway Bridge Design Code

GDF $=$ girder distribution factor

LRFD = load and resistance factor design

OHBDC $=$ Ontario Highway Bridge Design Code 
structural systems. The reliability analysis will also be applied to structural systems.

\section{Reliability-based calibration procedure}

One of the most important applications of the structural reliability methods is the development of the new generation design codes for bridges. The load and resistance factors are calculated so that the reliability of structures is at the predetermined target level. In particular, the calibration procedure used for the development of the first edition of OHBDC[2] was formulated by Nowak and Lind[13]. It was further expanded and applied in the development of other editions of OHBDC[2], AASHTO LRFD[1] and CHBDC[4], as described by Grouni and Nowak[14], Nowak and Grouni[15] and Nowak[16]. A similar approach was used in the development of the Eurocode[17].

For example, the calibration procedure applied in the development of the AASHTO LRFD Code[1] included the following steps:

(a) Selection of representative bridges. About 200 structures were selected from various geographical regions of the United States. These structures covered materials, types and spans which were characteristic for the region. Emphasis was placed on current and future trends, rather than very old bridges. For each selected bridge, load effects (moments, shears, tensions and compression) were calculated for various components. Load-carrying capacities were also evaluated.

(b) Establishing the statistical database for load and resistance parameters. The available data on load components, including results of surveys and other measurements, was gathered. Truck survey and weigh-in-motion (WIM) data were used for modeling live load. There is little field data available for dynamic load therefore a numerical procedure was developed for simulation of the dynamic bridge behavior. Statistical data for resistance included material tests, component tests and field measurements. Numerical procedures were developed for simulation of behavior of large structural components and systems.

(c) Development of load and resistance models. Loads and resistance are treated as random variables. Their variation is described by cumulative distribution functions (CDF) and correlation. For loads, the CDFs are derived using the available statistical database (Step $(b))$. Live load model includes multiple presence of trucks in one lane and in adjacent lanes. Multilane reduction factors were calculated for wider bridges. Dynamic load is modeled for single trucks and two trucks side by side. Resistance models were developed for girder bridges. The variation of the ultimate strength was determined by simulations. System reliability methods were used to quantify the degree of redundancy.

(d) Development of the reliability analysis procedures. Structural performance can be measured in terms of the reliability, or probability of failure. Limit states are defined as mathematical formulas describing the state (safe or failure). Reliability can be measured in terms of the reliability index, $\beta$. Reliability index was calculated using an iterative procedure. The developed load and resistance models (Step (c)) are part of the reliability analysis procedure.

(e) Selection of the target reliability index. Reliability indices were calculated for a wide spectrum of bridges designed according to the non-LRFD AASHTO[18]. The performance of existing bridges was evaluated to determine whether their reliability level is adequate. The target reliability index, $\beta_{\mathrm{T}}$, was selected to provide a consistent and uniform safety margin for all structures.

(f) Calculation of load and resistance factors. Load factors, $\gamma$, are calculated so that the factored load has a predetermined probability of being exceeded. Resistance factors, $\phi$, are calculated so that the structural reliability is close to the target value, $\beta_{\mathrm{T}}$.

\section{Bridge load models}

The development of a live load model is essential for a rational bridge design and/or evaluation code. The basic load combination for highway bridges is a simultaneous occurrence of dead load, live load, and dynamic load. The combinations involving other load components (wind, earthquake, collision forces) require a special approach which takes into account a reduced probability of a simultaneous occurrence of extreme values of several independent loads.

Dead load is the gravity load due to the self-weight of the structural and non-structural elements permanently connected to the bridge. Because of different degrees of variation, it is convenient to consider three components of dead load: weight of factory made elements (steel, precast concrete members), weight of cast-in-place concrete members, and weight of the wearing surface (asphalt). All components of dead load can be treated as normal random variables. The statistical parameters used by researchers in different projects vary, with the bias factor (ratio of mean to nominal), $\lambda=1.00-1.05$, and coefficient of variation, $V=0.04-0.10$, except for asphalt $V=0.15-0.30$.

The derivation of bridge load models is based on the studies performed in conjunction with the development of AASHTO LRFD Code[1] and 
OHBDC[2] as summarized by Nowak[19, 20] and Nowak and Hong[21]. Load models were developed on the basis of the available truck surveys and other measurements. The maximum 50-75 year live load was determined by exponential extrapolation of the extreme values obtained in the survey. Girder distribution factors were determined using finite element analysis. Dynamic load was modeled using the available test data.

Live load covers a range of forces produced by vehicles moving on the bridge. The effect of live load depends on many parameters including the span length, truck weight, axle loads, axle configuration, position of the vehicle on the bridge (transverse and longitudinal), number of vehicles on the bridge (multiple presence), girder spacing, and stiffness of structural members (slab and girders). The effect of these parameters is considered separately. Bridge live load is strongly site-specific. The variation is not only from country to country, but within a region, depending on local traffic volume and mix, legal load limits, and special conditions[22]. Therefore, the statistical parameters can also be site-specific.

In the development of a national bridge design code, the statistical parameters of live load are often assumed to be on a conservative side. Truck traffic data is taken for the location with high volume of heavy vehicles. The maximum expected live load moments and shears for various time periods can then be determined by extrapolation. For example, in the development of AASHTO LRFD[1], for 75 years, $\lambda=1.6-2.1$ (depending on span length) and $V=0.12[19,21]$. The nominal live load is represented by HS-20 truck HS20 loading consists of either three axles: 35,142 and $142 \mathrm{kN}$, spaced at $4.3 \mathrm{~m}$, or a uniformly distributed lane load of $9.3 \mathrm{kN} / \mathrm{m}$ with a moving concentrated force of $80 \mathrm{kN}$. In the new LRFD AASHTO Code[1], live load is a combination of HS-20 truck and a uniformly distributed load of $9.3 \mathrm{kN} / \mathrm{m}$. Therefore, the bias factor for live load is $\lambda=1.25-1.35$. A similar load model was used in the development of OHBDC[2] as presented by Nowak[20]. The maximum one-lane moment or shear is caused either by a single truck or two (or more) trucks following behind each other. For multiple truck occurrence, the important parameters are the headway distance and degree of correlation between truck weights. The analysis of two-lane loading involves the distribution of truck load to girders.

The dynamic load is a function of three major parameters: road surface roughness, bridge dynamics (frequency of vibration) and vehicle dynamics (suspension system). The analytical model was developed by Hwang \& Nowak[23] and verified by field tests by Nassif \& Nowak[24] and Kim \& Nowak[25]. It was observed that dynamic deflection is almost constant and it does not depend on truck weight. Therefore, the dynamic load, as a fraction of live load, decreases for heavier trucks, so that it does not exceed 0.15 of live load for a single truck and 0.10 of live load for two trucks side by side. The coefficient of variation of dynamic load is about 0.80 .

\section{Bridge resistance models}

The resistance of a bridge components has been modeled by tests, observations of existing structures and by numerical simulations. The causes of uncertainty about the structural resistance can be put into three categories[26]:

- Material: Strength of material, modulus of elasticity, cracking stress, and chemical composition.

- Fabrication: Geometry, dimensions, and section modulus.

- Analysis: Approximate method of analysis, idealized stress and strain distribution model.

Therefore, the resistance, $R$, can be considered as a product of the nominal resistance, $R_{\mathrm{n}}$, and three factors: material properties, $M$, fabrication (geometry), $F$, and professional/analysis, $P$,

$R=R_{\mathrm{n}} M F P$

The statistical data on resistance parameters can be based on the available material and component tests. The actual data vary depending on the source. In North America, the mechanical properties of structural steel, concrete, reinforcing steel and prestressing steel were provided by Ellingwood et al[26], Siriaksorn \& Naaman[27], and Kennedy \& Baker[28]. Flexural capacity of a girder can be established by simulation of moment-curvature relationship, as described by Tabsh \& Nowak[29]. The shear capacity of concrete components can be calculated using the modified compression field theory[30,31]. The statistical parameters for bridge girders were developed by Nowak et al[32], Nowak \& Yamani[33], and Tabsh \& Nowak[29], for noncomposite steel girders, composite steel girders, reinforced concrete $\mathrm{T}$-beams and prestressed concrete AASHTO-type girders. The resulting parameters are $\lambda=1.05-1.16$, and $V=0.07-0.16$.

\section{Reliability analysis}

Selection of the reliability analysis procedure is very important. The methods for calculation of the reliability index are described in the available literature, for example Refs[7,11]. The methods vary with regard to accuracy, required input data, computational effort and special features (time variance). The reliability can be used as an efficient criterion in selection of load and resistance factors. However, the same reliability analysis procedure should be used in calibration, the same for different 
materials and structural types. Otherwise, calculated $\beta$ 's cannot be considered as a fair basis for comparison.

In early code calibrations[13], the reliability index was calculated using the simple logarithmic formula

$\beta=\ln \left(m_{\mathrm{R}} / m_{\mathrm{Q}}\right) /\left(V_{\mathrm{R}}^{2}+V^{2}\right)^{1 / 2}$

In 1990s the reliability indices, $\beta$, have been calculated using an iterative procedure developed by Rackwitz \& Fiessler[6].

In the traditional reliability analysis, the analysis is performed for individual components. However, in many cases, a considerable advantage can be gained by use of the system reliability methods. The structure can be considered as a system of components. Systems approach allows to quantify the redundancy and complexity of the structure[34].

\section{Target reliability level}

The development of limit state codes and/or load and resistance factor design (LRFD) codes for the design and evaluation of bridges requires the knowledge of the target reliability level. The optimum safety level depends on the consequences of failure and cost of safety. Selection of the target reliability can be based on consideration of these two parameters. Target reliability indices calculated for newly designed bridges and existing structures are different for many reasons. Reference time period is different for newly designed and existing bridges. New structures are designed for 50 year lifetime and existing bridges are checked for 5 or 10 year periods. Load model, used to calculate reliability index depends on the reference time period. Maximum moments and shears are smaller for 5 or 10 year periods than for $50-75$ year lifetime. However, the coefficient of variation is larger for shorter periods. Single load path components require a different treatment than multiple load path components. In new designs, single load path components are avoided, but such components can be found in some existing bridges. Target reliability index is higher for single load path components.

Reliability indices calculated for existing bridges can be considered as the lower bounds of safety levels acceptable by the society. A drastic departure from these acceptable limits should be based on an economic analysis. The target reliability index depends on costs and has different value for a newly designed bridge and an existing one. In general, it is less expensive to provide an increased safety level in a newly designed structure. For bridges evaluated for 5 or 10 year periods (intervals between inspections), it is assumed that inspections help to reduce the uncertainty about the resistance and load parameters. Therefore, the reliability index can be lower for existing bridges evaluated for 5 or 10 year periods.

Optimum safety can be determined by minimization of the total expected cost (or maximization of the utility). The optimum safety level corresponds to the minimum total expected cost. The total cost includes the cost of investment (design and construction) and the expected cost of failure. The cost of failure includes not only the cost of repair or replacement but also the cost of interruption of use, and legal costs (liability in case of injuries). Because of economical reasons, it is convenient to differentiate between primary and secondary components in bridges. The difference between these components depends on the consequences of failure. Target reliability index for secondary components is lower than that for primary components.

Serviceability limit states (SLS) have a lower level of consequences of failure than ultimate limit states (ULS). Therefore, lower values of the target reliability index are selected for SLS than ULS. For the ultimate limit states, calculated reliability indices represent component reliability rather than system reliability. The reliability indices calculated for structural system are larger than for individual components by about 2 . Therefore, selection of the target reliability level should be based on consideration of the system. Then, target reliability index for components can be derived using the appropriate formulas. For serviceability limit states, reliability indices vary considerably depending on the limit state.

Reliability indices calculated for elements can serve as a basis for the selection of the target reliability index. Let $\beta_{\mathrm{e}}$ be an element reliability index and $\beta_{\mathrm{s}}$ be the system reliability index. For a single-path component, $\beta_{\mathrm{e}}=\beta_{\mathrm{s}}$. From the system reliability point of view, a multiple-path system can be considered as a parallel system of at least two elements. For such a system, if $\beta_{\mathrm{e}}=3.5$, the system reliability, $\beta_{\mathrm{s}}=5.3$, when elements are fully uncorrelated. However, the elements are usually partially correlated and therefore, $\beta_{\mathrm{s}}=3.5-5.5$, depending on the coefficient of correlation ( 3.5 for full correlation). The recommended target reliability indices for 5 year evaluations of multiple load path components are $\beta_{\mathrm{T}}=3.0$ and for single load path components $\beta_{\mathrm{T}}=3.5$. The corresponding $50-75$ year values are $\beta_{\mathrm{T}}=3.5$ for multiple path components and $\beta_{\mathrm{T}}=4.0$ for single-path components[2].

A primary component is a main structural element, failure of which causes the collapse of the whole structure. In case of bridges, girders are the primary components. It is assumed that the consequences of failure of primary components are about 10 times larger than those of secondary components. Therefore, the probability of failure of secondary components can be 10 times larger than for primary components. The resulting target reliability indices for secondary components are $\beta_{\mathrm{T}}=2.25$ for 5 year evaluation. $\beta_{\mathrm{T}}=2.50$ for 10 year evaluation and $\beta_{\mathrm{T}}=2.75$ for 50-75 year period[2].

Recommended values of the target reliability indices for design and evaluation of bridges are listed 
Table I Recommended target reliability indices for evaluation

$\begin{array}{cccc}\begin{array}{l}\text { Time period } \\ \text { (years) }\end{array} & \begin{array}{l}\text { Primary components } \\ \text { Single path }\end{array} & \begin{array}{l}\text { Secondary } \\ \text { Multiple path }\end{array} \\ \text { components }\end{array}$

in Table 1. The numbers are rounded off to the nearest 0.25 [2].

\section{Load and resistance factors}

The acceptance criteria in the selection of load and resistance factors is closeness to the target reliability level, $\beta_{\mathrm{T}}$. Optimum values of factored load and factored resistance correspond to the so-called design point, which can be determined using the Rackwitz \& Fiessler procedure[6]. For simplicity of the code, the load and resistance factors are rounded to the nearest 0.05 . In general, these factors can be different for each design case, even for load combinations including the same load components. An arbitrary decision is often made to minimize the number of different factors.

The efficiency of the reliability-based calibration is illustrated on the example of two recent projects: the development of AASHTO LRFD[1] and OHBDC[2]. The reliability indices were calculated for representative bridges designed using non-LRFD AASHTO[18] and calibrated LRFD AASHTO[1]. The results are shown in Fig. 1 for moments and Fig. 2 for shears. Similarly, the reliability indices were calculated for the OHBDC prior to calibration[2] and after calibration[2] and the results are presented in Figs. 3 and 4 for moments and shears, respectively.

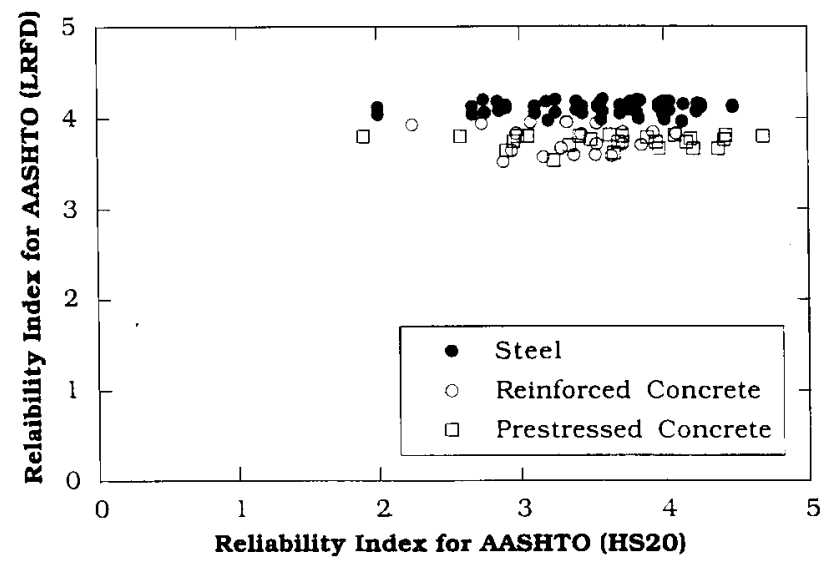

Fig. I Reliability indices for AASHTO prior to calibration (HS20) and after calibration (LRFD) — moment

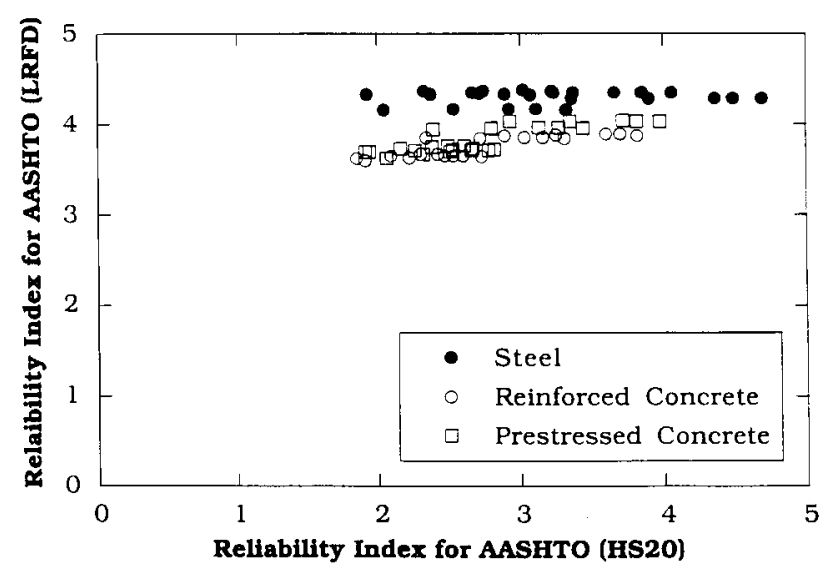

Fig. 2 Reliability indices for AASHTO prior to calibration (HS20) and after calibration (LRFD) — shear

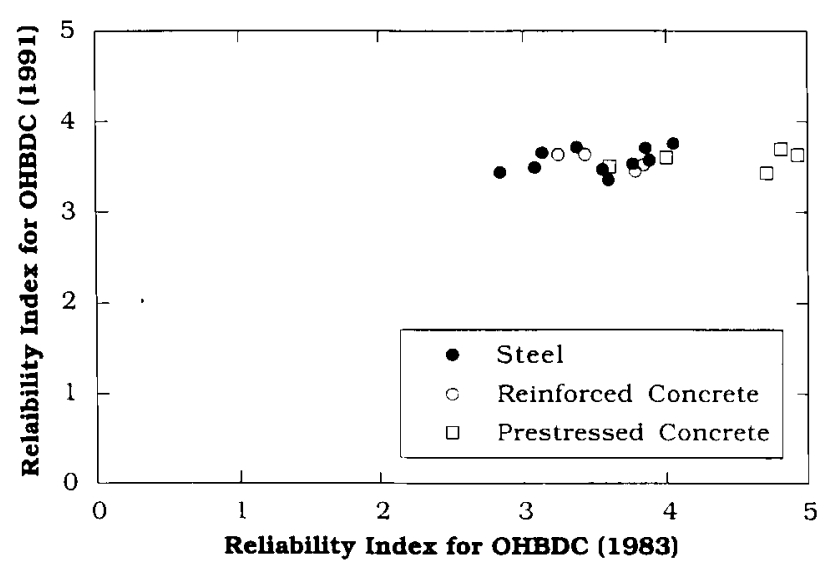

Fig. 3 Reliability Indices for OHBDC prior to calibration [2] and after calibration [2] - moment

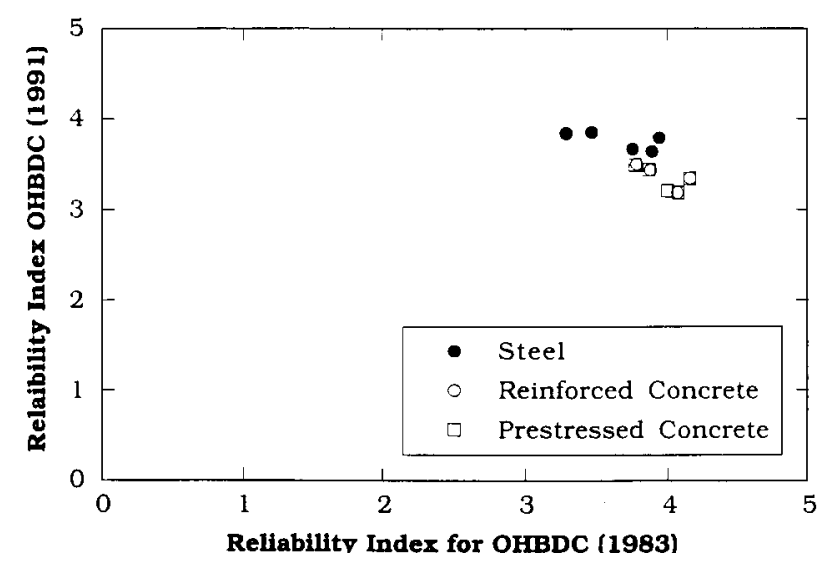

Fig. 4 Reliability indices for OHBDC prior to calibration [2] and after calibration [2] shear

\section{Conclusions and future research}

The structural reliability can serve as rational basis for calculation of load and resistance factors. Reliabilitybased code provide a uniform safety level for various bridges (materials and types). 
The available statistical database indicates that bridge live loads are strongly site-specific. There is a need for more unbiased truck surveys to verify the validity of the current load models. Further material tests are needed to provide a basis for simulation of the behavior of bridge components and systems. Field tests can be used to verify the current load distribution methods.

Current studies are focused on the analysis of individual components (girders). There is a need for consideration of the system behavior. This will allow to quantify the effect of redundancy, ductility, and load sharing in general.

\section{References and recommended reading}

* Special interest
** Exceptional interest

[I] AASHTO. LRFD bridge design specifications. Washington, DC: American Association of State Highway and Transportation Officials. 1994.

[2] OHBDC. Ontario highway bridge design code. Downsview, Ontario, Canada: Ministry of Transportation. 1979, 1983, 1991.

[3] Eurocode. 1993

[4] CHBDC. Canadian highway bridge design code. Canada, 2000, in press

[5] Hasofer AM \& Lind NC. Exact and invariant second-moment code format. Journal of Engineering Mechanics (ASCE) 1974: 100(EMI): III-I2I.

[6] Rackwitz R \& Fiessler B. Structural reliability under combined random load sequences. Computer and Structures 1978: 9: 489-494.

* [7] Thoft-Christensen P \& Baker MJ. Structural reliability theory and its application. Berlin: Springer, 1982. 267.

Excellent textbook on basic structural reliability.

[8] Augusti G, Baratta A \& Casciati F. Probabilistic methods in structural engineering. New York: Chapman \& Hall. 1984

[9] Madsen HO, Krenk S \& Lind NC. Methods of structural safety. New York: Prentice-Hall. 1986.

[10] Ang H-S \& Tang WH. Probability concepts in engineering planning and design, Vol II: decision, risk, and reliability. New York: Wiley. 1984.

[II] Melchers RE. Structural reliability analysis and prediction, Chichester, England: Ellis Horwood. 1987.

[1 2] Thift-Christensen P \& Murotsu Y. Application of structural systems reliability theory. New York: Springer. 1986: 350.

** [13] Nowak AS \& Lind NC. Practical bridge code calibration. Journal of the Structural Division (ASCE) 1979: 105: 2497-2510

Example of the reliability-based calibration of a bridge design code.

** [14] Grouni HN \& Nowak AS. Calibration of the Ontario highway bridge design code. The Canadian Journal of Civil Engineering 1984: I I (4): 760-770.

A practical example of reliability-based calibration.

** [15] Nowak AS \& Grouni HN. Calibration of the OHBDC-199I. Canadian Journal of Civil Engineering 1994; 21: 25-35.

Recent example of the reliability-based calibration of a bridge design code.

** [16] Nowak AS. Calibration of LRFD bridge code. Journal of Structural Engineering (ASCE) 1995; I 2 I (8): |245-125|.

Recent example of the reliability-based calibration of a bridge design code.

[17] IABSE. Colloquium on Eurocodes. Delft, The Netherlands, IABSE Report (Vol. 74) March 1996.

[18] AASHTO. 1992.

* [19] Nowak AS. Live load model for highway bridges. Journal of Structural Safety 1993; 13(1 + 2): 53-66.

Summary of bridge live load model, derivation of statistical parameters.

* [20] Nowak AS. Load model for bridge design code. Canadian Journal of Civil Engineering 1994; 2 I: 36-49.

Summary of load model, derivation of statistical parameters.
* [21] Nowak AS \& Hong Y-K. Bridge live load models. Journal of Structural Engineering (ASCE) 1991; 117 (9): 2757-2767.

Summary of bridge live load model, derivation of statistical parameters.

[22] Kim et al 1994.

* [23] Hwang E-S \& Nowak AS. Simulation of dynamic load for bridges. Journal of Structural Engineering (ASCE) 1991; II7(5): 1413-1434.

Good basis for bridge dynamic load model.

* [24] Nassif H \& Nowak AS. Dynamic load spectra for girder bridges. Transportation Research Record 1995: 1476: 69-83.

Field data for dynamic load on bridges.

* [25] Kim S-J \& Nowak AS. Load distribution and impact factors for I-girder bridges. Journal of Bridge Engineering (ASCE) 1997; 2(3): 97-104.

Field data for bridge dynamic load model and girder distribution factors.

** [26] Ellingwood B, Galambos TV, MacGregor JG \& Cornell CA.

Development of a probability based load criterion for American national standard A58.

National Bureau of Standards, NBS Special Publication 577, Washington, DC, 1980.

Good source of information on statistical parameters of loads and resistance.

[27] Siriaksorn A \& Naaman AE. Reliability of partially prestressed beams at serviceability limit states. Report No. 80-I, University of Illinois at Chicago Circle, Chicago, June 1980.

[28] Kennedy DJL \& Baker KA. Resistance factors for steel highway bridges. Canadian Journal of Civil Engineering 1984; II: 55-67.

* [29] Tabsh SW \& Nowak AS. Reliability of highway girder bridges. Journal of Structural Engineering (ASCE) 199I: I I7(8): 2373-2388.

Derivation of parameters for resistance, reliability analysis.

[30] Collins MP \& Michell D. Prestressed concrete structures. Englewood Cliffs, NJ: Prentice-Hall.

[3I] Vecchio FJ \& Collins MP. The modified compression field theory for reinforced concrete elements subjected to shear. ACl Journal | 986: 83 (2): 219-23।.

* [32] Nowak AS, Yamani AS \& Tabsh SW. Probabilistic models for resistance of concrete bridge girders. ACl Structural Journal I994: 9I (3): 269-276.

Derivation of parameters of resistance for concrete bridge girders.

* [33] Nowak AS \& Yamani AS. Reliability analysis for girder bridges. Structural Engineering Review 1995; 7(3): 25I-256.

Derivation of statistical parameters for reistance, in particular shear.

** [34] Frangopol DM \& Nakib R. Redundancy evaluation of steel girder bridges. Proceedings of ICOSSAR (Vol 3), San Francisco. 1989.

A good paper dealing with system reliability.

[35] AASHTO. Standard specifications for highway bridges. Washington, DC: American Association of State Highway and Transportation Officials. 1996.

[36] Ayyub BM \& McCuen RH. Probability, statistics, and reliability for engineers. Boca Raton: CRC Press. 514.

* [37] Benjamin JR \& Cornell CA. Probability, statistics, and decision for civil engineers. New York: McGraw-Hill. 684.

Excellent introduction to probability and statistics.

[38] Cornell CA. A probability based structural code. ACl Journal 1969: 66(12): 974-985.

* [39] Frangopol DM, Ghosn M, Hearn G \& Nowak AS. Structural reliability in bridge engineering. Journal of Bridge Engineering (ASCE) 1998: 4(4): |5|-|54.

Summary of current research activities and future research needs.

** [40] Ghosn M \& Moses F. Reliability calibration of bridge design code. Journal of Structural Division (ASCE) I I 2(ST4): 1986: 745-763.

Many useful ideas for reliability-based calibration

[4I] Hwang E-S \& Nowak AS. Dynamic analysis of girder bridges. Transportation Research Record 1990: 1223: 85-92.

* [42] Kulicki JM \& Mertz DR. Development of comprehensive bridge specifications and commentary. Final Report submitted to NCHRP, December 1993.

Highlights of the development of AASHTO LRFD code.

[43] Lind NC \& Davenport AG. Towards practical application of structural reliability theory. In: Probabilistic design of reinforced concrete buildings (American Concrete Institute Special Publication 31) 1972: 63-110.

[44] Nassif H \& Nowak AS. Dynamic load for girder Bridges under normal traffic. Archives of Civil Engineering 1996; XLII (4): 38I-400. 
* [45] Nowak AS \& Szerszen MM. Bridge load and resistance models. Engineering Structures Journal 1998; 20(1 I): 985-990.

Summary of load and resistance parameters.

[46] Nowak AS, Hong Y-K \& Hwang E-S. Modeling live load and dynamic load for bridges. Transportation Research Record 1991; 1289: 110-118.

[47] Nowak AS \& Zhou J-H. System reliability models for bridges. Journal of Structural Safety 1990: 7: 247-254.

[48] Nowak AS \& Tharmabala T. Bridge reliability evaluation using load tests. Journal of Structural Engineering (ASCE) 1988: I I4(I0): 2268-2279.

[49] Sandberg HR, Galambos C, Nowak AS, Moses F, Dorton

R \& Cassano R. Load and resistance factor design for bridges. ACl Concrete International 1988: 10(5): 48-55.
* [50] Tharmabala T \& Nowak AS. Mathematical models for bridge reliability. The Canadian Journal of Civil Engineering 1987: 14(2): I55-162.

System reliability models applied for bridges

[5 I] Zhou J-H \& Nowak AS. Integration formulas for functions of random variables. Journal of Structural Safety 1988: 5: 267-284.

* [52] Zhou J-H \& Nowak AS. Reliability analysis for bridge systems. Journal of Forensic Engineering 1990: 2(4): 449-457.

System reliability analysis for girder bridges.

\section{Andrzej S Nowak}

Department of Civil and Environmental Engineering,

University of Michigan,

2370 GG Brown, Ann Arbor,

MI 48109-2I25, USA

\section{Maria M Szerszen}

Department of Civil and Environmental Engineering,

University of Michigan,

2370 GG Brown, Ann Arbor,

MI 48109-2।25, USA 